\title{
BMJ Open Prevalence of post-traumatic stress disorder and associated factors among Koshe landslide survivors, Addis Ababa, Ethiopia: a community-based, cross-sectional study
}

\author{
Sintayehu Asnakew, ${ }^{1}$ Shegaye Shumet, ${ }^{\circ} 2$ Worknesh Ginbare, ${ }^{3}$ Getasew Legas, ${ }^{1}$ \\ Kalkidan Haile ${ }^{4}$
}

To cite: Asnakew S, Shumet S, Ginbare W, et al. Prevalence of post-traumatic stress disorder and associated factors among Koshe landslide survivors, Addis Ababa, Ethiopia: a community-based, crosssectional study. BMJ Open 2019;9:e028550. doi:10.1136/ bmjopen-2018-028550

\section{- Prepublication history for} this paper is available online. To view these files, please visit the journal online (http://dx.doi. org/10.1136/bmjopen-2018028550).

Received 17 December 2018

Revised 31 May 2019

Accepted 3 June 2019

Check for updates

(c) Author(s) (or their employer(s)) 2019. Re-use permitted under CC BY-NC. No commercial re-use. See rights and permissions. Published by BMJ.

${ }^{1}$ Psychiatry, Debretabor University, Debretabor, Ethiopia ${ }^{2}$ Psychiatry, University of Gondar, Gondar, Ethiopia

${ }^{3}$ Psychiatry, Amanuel Mental Specialized Hospital, Addis Ababa, Ethiopia

${ }^{4}$ Psychiatry, Debremarkos hospital, Debremarkos, Ethiopia

Correspondence to

Mr. Shegaye Shumet; shumetshegaye@yahoo.com

\section{ABSTRACT}

Objectives To assess the prevalence of post-traumatic stress disorder (PTSD) and associated factors among the survivors of Koshe landslide, Addis Ababa, Ethiopia, 2018. Design Community-based cross-sectional design. Setting Koshe landslide, Addis Ababa, Ethiopia. Participants We recruited 830 participants for interviews using the simple random sampling technique.

Measurement We collected data by face-to-face interviews. The civilian version of the PTSD checklist was used to measure the symptoms of the disorder. The Perceived Stress Scale and the 0slo-3 social support instruments were used to assess the factors. Coded variables were entered into Epi data V.4.2 and exported to SPSS V.24 for analysis. Bivariate and multivariate logistic regressions with $\mathrm{OR}$ and $95 \% \mathrm{Cl}$ were employed.

Result A total of 830 participants were interviewed, with a response rate of $98.2 \%$. The prevalence of PTSD was $37.3 \%$ with $95 \% \mathrm{Cl} 34.1$ to 40.8 . In the multivariate logistic regression, female sex (adjusted odds ratio $(A O R)=1.74,95 \% \mathrm{Cl} 1.21$ to 2.50 ), divorce ( $A 0 R=2.08,95 \% \mathrm{Cl} 1.26$ to 3.43 ), sustained physical injury (AOR=8.28, 95\% Cl 5.04 to 13.61), history of mental illness $(A O R=5.55,95 \% \mathrm{Cl} 2.30$ to 13.36), family history of mental illness (AOR=2.82, 95\% $\mathrm{Cl} 1.48$ to 5.37), poor social support ( $\mathrm{AOR}=3.64,95 \% \mathrm{Cl} 1.99$ to 6.69 ) and high perceived stress (AOR=3.08, 95\% $\mathrm{Cl} 1.43$ to 6.64 ) were associated with PTSD.

Conclusion and recommendations The prevalence of PTSD among the survivors of Koshe landslide was high. We recommend that an early PTSD-focused regular screening be carried out by trained health professionals; linkage with mental health service providers also needs to be considered.

\section{INTRODUCTION}

Post-traumatic stress disorder (PTSD) is a mental health problem that occurs following a traumatic event in which the individual experience, witnesses, is confronted with either actual or imagined loss of life or serious injury which results in a response of
Strengths and limitations of this study

- The nature of cross-sectional design, which might have only partially accounted for durable temporal relationships.

- Social and recall biases might have interfered with decisions respondents made when completing the questionnaire.

- The post-traumatic stress disorder checklist-civilian version scale used in the current study can serve as a reference in subsequent studies since it has good internal consistency.

fear, helplessness or horror. ${ }^{1}$ In order to be diagnosed with PTSD, a person must re-experience the trauma, avoidance of trauma-related stimuli, excessive arousal and negative alterations in cognition and mood which occur within a month after the event. ${ }^{2}$ A disaster is a traumatic event that might have been experienced by many people and causes different mental and physical health consequences. ${ }^{3}$ A survey study conducted on US residents, $13 \%$ of the participants reported a lifetime exposure to natural or human-generated disasters. ${ }^{4}$ Several studies conducted among adults showed that there was an increasing psychological distress after natural disasters. ${ }^{5}$ Although the consequences of a disaster included a wide range of psychopathology, a review study indicated that PTSD is the most commonly investigated and frequently occurring psychopathology following disaster. ${ }^{6}$

About 8 million adults had PTSD during a given year worldwide. ${ }^{7}$ Over 51 million people are being forcibly displaced worldwide, of whom 16.7 million were displaced outside their home countries, and this may lead to a stress-related disorders. ${ }^{8}$ The global disease 
burden report attributed about $14 \%$ of the burden to neuropsychiatric disorders, mostly because of the longterm disabling nature of depression and other common mental disorders like PTSD. ${ }^{9}$ According to World Health Report 2001, $\sim 0.4 \%$ of the total years lived with disability (YTD) followed PTSD, and the estimated burden increased to $0.6 \%$ YLD globally. ${ }^{10}$ Data in USA showed the lifetime prevalence of PTSD was $8 \%$ in the general population. The lifetime prevalence rate was $10 \%$ in women and $4 \%$ in men. ${ }^{11} \mathrm{~A}$ study on Israelis aged 18 years and above and exposed to terrorism showed that the average prevalence of PTSD was 9.4\%, 16.2\% for women and 2.4\% for men. ${ }^{12}$ The global economic burden of stress-related mental illness is expected to rise in the coming decade. The global disease burden study of WHO estimates that mental illness, including stress-related disorders, will be the second leading cause of disability by the year $2020 .{ }^{13}$

The prevalence rate of PTSD in developing countries is higher compared with the developed ones. A study conducted among a geographically diverse sample of Mexican adults estimated the prevalence of PTSD at $19 \% .{ }^{14}$ Different studies in Africa showed that PTSD could still be a public health concern for several years after the civil conflict and natural disaster. Reviews of community-based studies in South Africa showed that trauma exposure was higher in low-income countries than in their counterparts. ${ }^{15}$ Another study in Uganda during an active conflict showed that PTSD prevalence varied between $18 \%$ and $54 \%$ in the general population. ${ }^{16}$

PTSD is a public health issue that contributes to poverty, lack of employment, insecure living circumstances, change in the social network and is highly associated with low quality of life. ${ }^{17} 18$ Factors that contribute to the development of PTSD have been classified into pre-existing factors like family history of mental illness, substance history as well as the traumatic event itself, and post-trauma factors, such as lack of social support. ${ }^{19}$

There was a devastating garbage landslide in Addis Ababa, Ethiopia, in the area of Koshe garbage land fill on 11 March 2017. The catastrophic slope collapse killed >113 people who were living around the landfill and injured several others. The debris stood from a height of $20 \mathrm{~m}$ beyond the actual toe line of the landfill, destroying a minimum of 50 houses. ${ }^{20} 21$ The phenomenon occurred in the early morning hours of 11 March and buried a number of makeshift homes under tons of refuse as reported by Eddie Haywood (March 2017). Koshe landfill is a large man-made mount formed from vast rubbish dump on the outskirts of Addis Ababa, the capital of Ethiopia. Hundreds of people used to attempt to make a living by collecting refuse at the landfill site and selling it. Some people even lived around the rubbish dump permanently. Even though landslides sometimes happened in Ethiopia, a man-made garbage hill slide like this was quite. The landslide left a negative sequel on the victims' socioeconomic and psychological conditions, for example, in terms of housing, job and loss of family members.
Disasters including man-made mishaps have negative impacts on the mental health of affected individuals. ${ }^{22}$ PTSD is the most common psychopathology and notable public health matter that follows trauma/disaster. Although PTSD is highly prevalent among postdisaster settings, no studies have been done on the prevalence of PTSD among Koshe landslide survivors, Addis Ababa, Ethiopia. So, determining the prevalence of PTSD and associated factors among the survivors is important for early intervention and the reduction of the burden of PTSD and to improve the victims' quality of life.

\section{Objective}

This study set out to assess the prevalence of PTSD and associated factors among the survivors of Koshe landslide, Addis Ababa, Ethiopia, 2018.

\section{METHODS AND MATERIALS}

\section{Study settings and period}

A community-based, cross-sectional study was conducted in May and June 2018. The study was conducted at Koshe (dirt), a large open landfill with a surface area of 25 hectares which used to receive 300000 tons of solid waste from Addis Ababa, the capital of Ethiopia, annually as reported by Clague 2017. It was the only dumping site available for the entire capital city with more than three million inhabitants. It has been located in the southwestern part of Addis Ababa bounded by Nefas Silk-Lafto and Kolfie subcities. The area was a dumping ground for Addis Ababa's rubbish for more than five decades, hosting hundreds of rubbish pickers who sell materials recovered from the waste. Some people even live around the site permanently.

\section{Study participants and sampling}

We used the multistage sampling technique to select 830 participants. To reach households, the simple random sampling technique (computer-generated random number) was employed. In each of the areas, household lists were obtained from the kebeles/wards/officesand health extension workers. We proportionally allocated the sample size to Kilinto, Asko, Addis Hiwot and Koshe garbage dumping area, where victims temporarily settled. Members of the selected households were further sorted for interviews. In case of more than one eligible participant in a household, the lottery method was used to choose one.

The study included participants aged 15 years and above during data collection in the area. There were a total of 5316 people in $\sim 1035$ households. Individuals seriously ill and unable to communicate were excluded.

\section{Sample size determination}

We determined the sample size by using the single population proportion formula with the assumptions of $48 \%$ prevalence of PTSD from studies conducted in South Sudan, ${ }^{23} 0.48 \mathrm{P}, 1.96 \mathrm{Z}$ (standard normal distribution), 
$95 \% \mathrm{CI}, \alpha=0.05$ and a $10 \%$ non-response rate. Accordingly, a representative/probabilistic sample was calculated to be 423 . After considering design effect, the total sample was 846 .

\section{Study variables}

The dependent variable was PTSD measured by the 17 items of the PTSD checklist-civilian version (PCL-C). We measured PTSD as a dichotomous variable (yes/ no). Independent variables included sociodemographic factors (age, sex, marital status, ethnicity, religion, educational and occupational status), clinical variables (family history of mental illness, previous history of mental illness and childhood trauma), trauma-related factors (trauma exposure, perceived life threat), substance-related factors (alcohol consumption, cigarette smoking, khat chewing), awhile psychosocial factors embraced social support and stressful life events.

\section{Data sources and measurement}

Data were collected by face-to-face interviews using a semistructured questionnaire by four trained data psychiatry nurses by means of the Amharic version of the tool for a month. The questionnaire was designed in English and translated to Amharic and back to English to maintain consistency. Data collectors were trained on how to interview participants and explain unclear questions and the purpose of the study. Furthermore, they were made aware about ethical principles, such as confidentiality/ anonymity/data management, and securing respondents' informed consent for participation.

PTSD was measured using the PCL-C. The PCL is a standardised self-report rating scale for PTSD comprising 17 items that correspond to the key Diagnostic and Statistical Manual of Mental Disorders-IV symptoms of PTSD. A total symptom severity score (range $=17-85$ ) was obtained by summing the scores from each of the 17 items. It had a Likert response options ranging from ${ }^{1}$ 'not at all' to 'extremely' and a cut-off $\geq 50$, that is, garbage landslide victims had PTSD symptoms. ${ }^{24}$ We adapted this instrument from a study conducted on Somali and Oromo Ethiopians in Minnesota. ${ }^{25}$ It showed a high internal consistency, reliability and a strong correlation with PTSD diagnosis. We conducted a reliability analysis for the PCL-C questionnaire (Amharic version) and that it a had high score (Cronbach's $\alpha=0.94$ ).

\section{Social support}

Social support was measured using the Oslo 3-items social support scale with scores ranging from 3 to 14 : 3-8=poor social support; 9-11=intermediate social support; and 12-14=strong social support. ${ }^{26}$

\section{Individual stress levels}

Individual stress levels were measured using the Perceived Stress Scale (PSS). The questions in this scale asked about feelings and thoughts last month. PSS was measured with likert type scale ranging from (0) 'never' to ${ }^{4}$ 'very often' and individuals with higher scores indicating higher perceived stress. ${ }^{27}$

\section{Substance use history}

To examine substance use history, respondents were asked: 'Have you ever used any substance in the last 3 months or in your lifetime?' and the responses were yes $/$ no. $^{28}$

\section{History of mental illness}

To examine history of mental illness, respondents were asked: 'Have you ever been diagnosed with mental illness and treated' and responses were yes/no.

\section{Family history of mental illness}

To examine family history of mental illness, respondents were asked: 'Do you know a family member who had experienced a mental illness?'

\section{Experiencing childhood trauma}

To examine childhood trauma, respondents were asked: 'Have you experienced childhood physical and sexual abuse and neglect' and responses were yes/no.

\section{Items on sociodemographic factors}

Items on sociodemographic factors (age, sex, ethnicity, religion, marital status, educational status and occupational status) were adopted from a variety literature.

\section{Data processing and analysis}

All collected data were checked for completeness and consistency and entered into Epi-data V.4.2 and then exported to SPSS for windows V.24 for analysis.

We computed descriptive, bivariate and multivariate logistic regression analyses to see the frequency distribution and to test the association between independent and dependent variables, respectively. Factors associated with PTSD were selected during the bivariate analysis with a $\mathrm{p}<0.05$ for further analysis in the multivariable logistic regression analysis. In the multivariable logistic regression analysis, variables with $\mathrm{p}<0.05$ at $95 \%$ CI with adjusted OR were considered as statistically significant.

\section{Ethical consideration}

Permission was obtained from the Addis Ababa Administration Health Bureau Ethical Committee. We received written informed consent from study participants and assent from officially authorised foster parents after explaining the purpose of the study. Confidentiality was maintained by omitting personal identifiers.

\section{Patient and public involvement}

In the current study, participants were people who survived the Koshe landfill, Addis, Ababa, Ethiopia; patients were excluded; participants were not involved in the study design and recruitment. The results of this study will be disseminated to the Federal Ministry of Health, Addis Ababa Health Bureau and Kolfe subcity Health Department for timely management of survivors. 
Table 1 Sociodemographic characteristics of study participants among residents of Koshe area, Addis Ababa, Ethiopia, $2018(\mathrm{n}=830)$

\begin{tabular}{|c|c|c|}
\hline Characteristics & Frequency & Percentage \\
\hline \multicolumn{3}{|l|}{ Age (years) } \\
\hline $15-40$ & 675 & 81.3 \\
\hline$>40$ & 155 & 18.7 \\
\hline \multicolumn{3}{|l|}{ Sex } \\
\hline Female & 491 & 59.2 \\
\hline Male & 339 & 40.8 \\
\hline \multicolumn{3}{|l|}{ Marital status } \\
\hline Married & 428 & 51.6 \\
\hline Single & 249 & 30 \\
\hline Divorced & 131 & 15.8 \\
\hline Others ${ }^{\star}$ & 22 & 2.7 \\
\hline \multicolumn{3}{|l|}{ Ethnicity } \\
\hline Amhara & 404 & 48.7 \\
\hline Tigray & 138 & 16.6 \\
\hline Gurage & 135 & 16.3 \\
\hline Oromo & 123 & 14.8 \\
\hline Others $†$ & 30 & 3.6 \\
\hline \multicolumn{3}{|l|}{ Religion } \\
\hline Orthodox & 502 & 60.5 \\
\hline Muslim & 195 & 23.5 \\
\hline Protestant & 94 & 11.3 \\
\hline Catholic & 39 & 4.7 \\
\hline \multicolumn{3}{|l|}{ Educational status } \\
\hline Cannot read and write & 153 & 18.4 \\
\hline Primary school & 366 & 44.1 \\
\hline Secondary school & 185 & 22.3 \\
\hline Diploma and above & 126 & 15.2 \\
\hline \multicolumn{3}{|l|}{ Occupational status } \\
\hline House wife & 131 & 15.8 \\
\hline Employed & 472 & 56.9 \\
\hline Student & 110 & 13.3 \\
\hline Jobless & 117 & 14 \\
\hline
\end{tabular}

*Separated, widowed. †Silte, Hadya.

\section{RESULT}

A total of 830 respondents took part with a response rate of $98.2 \%$. The majority of the respondents, $491(59.2 \%)$, were female. The mean age of the respondents was 33 (SD \pm 12 ) years; $675(81.3 \%)$ were in the age range of 15-40 years; 428 (51.6\%) were married; $502(60.5 \%)$ were Orthodox Christian and 404 (48.7\%) Amhara by ethnicity. Regarding occupation, more than half (56.6\%) were employed (table 1).

A small number, $55(6.6 \%)$ of the participants had history of mental illness, $202(24.3 \%)$ childhood physical
Table 2 Distribution of trauma-related factors of the respondents in Koshe, Addis Ababa, Ethiopia, 2018 ( $n=830)$

\begin{tabular}{lll}
\hline Characteristics & Frequency & Percentage \\
\hline $\begin{array}{l}\text { Sustaining physical injury } \\
\begin{array}{l}\text { Witnessing the death of families or } \\
\text { friends }\end{array}\end{array}$ & 166 & 20 \\
$\begin{array}{l}\text { Witnessing physical injury of families or } \\
\text { friends }\end{array}$ & 569 & 63.4 \\
\hline $\begin{array}{l}\text { Property destruction } \\
\text { Thinking, they may die }\end{array}$ & 240 & 28.9 \\
\hline $\begin{array}{l}\text { Perceived life threat } \\
\quad \text { Low perceived stress }\end{array}$ & 546 & 65.8 \\
\hline $\begin{array}{l}\text { Moderate perceived stress } \\
\text { High perceived stress }\end{array}$ & 185 & 22.3 \\
\hline
\end{tabular}

abuse and neglect experience and 79 (9.5\%) family history of mental illness.

Of the respondents, $569(68.6 \%)$ witnessed physical injury of families or friends, and about $166(20 \%)$ sustained physical injury and $581(70 \%)$ moderate perceived life threat (table 2).

Out of the total 830 participants, nearly half $(48 \%)$ had poor social support and the majority, 659 (79.4\%), experienced at least one stressful life event (table 3).

Regarding substance-related factors, nearly threefourths, $602(72.5 \%)$ consumed alcohol, and 516 $(62.20 \%)$ were doing that at the moment; $164(19.80 \%)$ smoked, and 102 (12.30\%) were smoking; 129 (15.5\%) used khat (leaves) and $102(12.30 \%)$ were using it during the study.

\section{Prevalence of PTSD}

The prevalence of PTSD among participants was $37.3 \%$ (95\% CI 34.1 to 40.8 ).

\section{Factors associated with PTSD}

To determine the association of independent variables with PTSD, bivariate and multivariate binary logistic regression analyses were carried out. In the bivariate analysis, factors including female sex, $>60$ years of age, divorce, history of mental illness, family history of mental illness, childhood physical trauma and neglect, physical injury, witnessing the death and physical injury of families or friends, property destruction, fear of death, poor social

Table 3 Distribution of psychosocial factors of the study participants among residents of Koshe, Addis Ababa, Ethiopia, 2018 ( $n=83)$

\begin{tabular}{llll}
\hline Characteristics & Category & Frequency & Percentage \\
\hline Social support & Poor & 398 & 48 \\
& Moderate & 324 & 39 \\
& Strong & 108 & 13 \\
\multirow{2}{*}{ Stressful life events } & Yes & 659 & 79.4 \\
& No & 171 & 20.6 \\
\hline
\end{tabular}


support and high perceived life threat were significantly associated with PTSD at a $p<0.05$. These factors were entered into the multivariable logistic regression model to control confounding effects.

The result of the multivariate analysis showed that female sex, divorce, history of mental illness, family history of mental illness, physical injury, poor social support and high perceived life threat were significantly associated with PTSD at a $\mathrm{p}<0.05$. Female sex was 1.7 times more likely to develop PTSD compared with male sex (AOR $=1.7,95 \%$ CI 1.2 to 2.5). The odds of developing PTSD were 2.1 times higher among divorcees compared with the married ones (AOR=2.1, 95\% CI 1.3 to 3.4). The odds of developing PTSD were 5.6 times higher among participants who had history of mental illness compared with those who had no such history (AOR=5.6, 95\% CI 2.3 to 13.4). The likelihood of developing PTSD was 2.8 times higher among respondents who had family history of mental illness compared with those who had no family history of mental illness (AOR=2.8, 95\% CI 1.5 to 5.4). The odds of developing PTSD were 8.3 times higher among respondents who sustained physical injury than those who had not (AOR $=8.3,95 \%$ CI 5.0 to 13.6). Respondents who had poor social support were 3.6 times more likely to develop PTSD compared with those who had strong social support (AOR=3.6, 95\% CI 2.0 to 6.7). The odds of developing PTSD were 3.1 times higher among respondents who had high perceived stress than those who had low perceived stress (AOR=3.1, 95\% CI 1.4 to 6.6) (table 4).

\section{DISCUSSION}

PTSD is the most common psychopathology and important public health matter after experiencing trauma/disaster. We found that, for the entire sample, the garbage landslide had a negative impact on exposed individuals' mental health in terms of housing, income, jobs and family problems resulting from the event. This study found that a number of people met the criteria for post-trauma stress symptomatology. Some $37.3 \%$ of people who experienced the incident presented with PTSD symptoms according to the PCL-C. Our finding was consistent with reports of studies on people exposed to natural disasters, such as $36.3 \%$ among earth quack victims in Kerman, 35.4\% Syrian refugees in Lebanon, $34.9 \%$ in Turkey and $34.3 \%$ among the bombing victims of Oklahoma city, USA. ${ }^{89-31}$ Conversely, this finding was lower than the $48 \%$ noted in South Sudan, $75.6 \%$ among the Rana Plaza building collapse victims in Bangladesh, 57\% in Saudi Arabia, 83.7\% in Croatia and Serbia former Yugoslavia, Germany and UK, 59.4\% in Fukushima nuclear disaster, Japan. ${ }^{18} 23$ 32-34 The possible reason for this difference might be the use of different instruments and cut-off points to measure PTSD, exposure to multiple trauma, study design and the nature and magnitude of the accidents covered in the study.

On the other hand, our estimations are higher than findings in other countries, for example, $11.8 \%$ in northern Uganda, $18.8 \%$ in Serbia, $29.3 \%$ in Southern
Lebanon and $9.1 \%$ in sothern Brazil. ${ }^{35-38}$ The possible reason for this variation might be difference in instruments. That is, the other study used general health questionnaire (GHQ)-12, structured clinical interview, mini-international neuropsychiatric interview (MINI), the modified version of the composite international diagnostic interview, while we utilised the PCL-C. The other variation might be due to the methods they used for data collection (structured telephone interview) and conducting of studies late after the trauma.

Female sex, being divorce, history of mental illness, family history of mental illness, sustained physical injury, poor social support and high perceived life threat were significantly associated with PTSD. The greater likelihood of PTSD among women than men in our work was similar to the reports of other studies, ${ }^{29} 3132$ 39-41 possibly because females experience sexual assaults and child sexual abuse more than males. Hence, being exposed to such trauma involves more risk than other trauma in causing PTSD. ${ }^{42}$

Divorcees were more likely to develop PTSD than married respondents. Participants who lost their partners and needed to support families, especially small children, single handed were more stressed. Our finding was supported by that of a study in Serbia. ${ }^{36}$

History of mental illness was also significantly associated with PTSD. Participants with history of mental illness might have more neurochemical imbalance and neuronal damage compared with those who had no history of mental illness. As a result, they might be prone to develop PTSD after the event. This finding was supported by results of studies conducted in various countries. 3134394344

The odds of developing PTSD was 2.8 times higher among respondents who had family history of mental illness than those who had no such illness. The possible explanation might be the inheritance of the serotonin transporter gene as well as genes associated with the hypothalamic-pituitary-adrenal axis and psychological factors which make participants more highly predisposed to PTSD. ${ }^{42}{ }^{45}$ This finding was consistent with the results of studies conducted in South Korea. ${ }^{43} 44$

Moreover, experiencing physical injury was a stronger predictor of PTSD compared with those who experienced no such injuries during the catastrophe. The finding was similar to the results of other studies. ${ }^{29} 3241$ The possible explanation for the similarity could be the presence of scars, the impaired part may remind the trauma and cause reliving it and victims may believe that the traumatic event has left its marks behind, and the body could keep clinging to unresolved issues. The odds of developing PTSD was 3.6 times higher among individuals who had poor social support than strong social support. The finding is similar to results of studies conducted in Southern Brazil and Mexico. ${ }^{38}{ }^{46}$ Lack of help to compensate for physical incapacity, emotional support and someone to talk with about the traumatic experience or to turn to for advice could increase the risk of PTSD. ${ }^{47}$

Participants who had high perceived stress were more likely to develop PTSD compared with respondents who 
Table 4 Factors associated with PTSD among residents of Koshe, Addis Ababa, Ethiopia, $2018(n=830)$

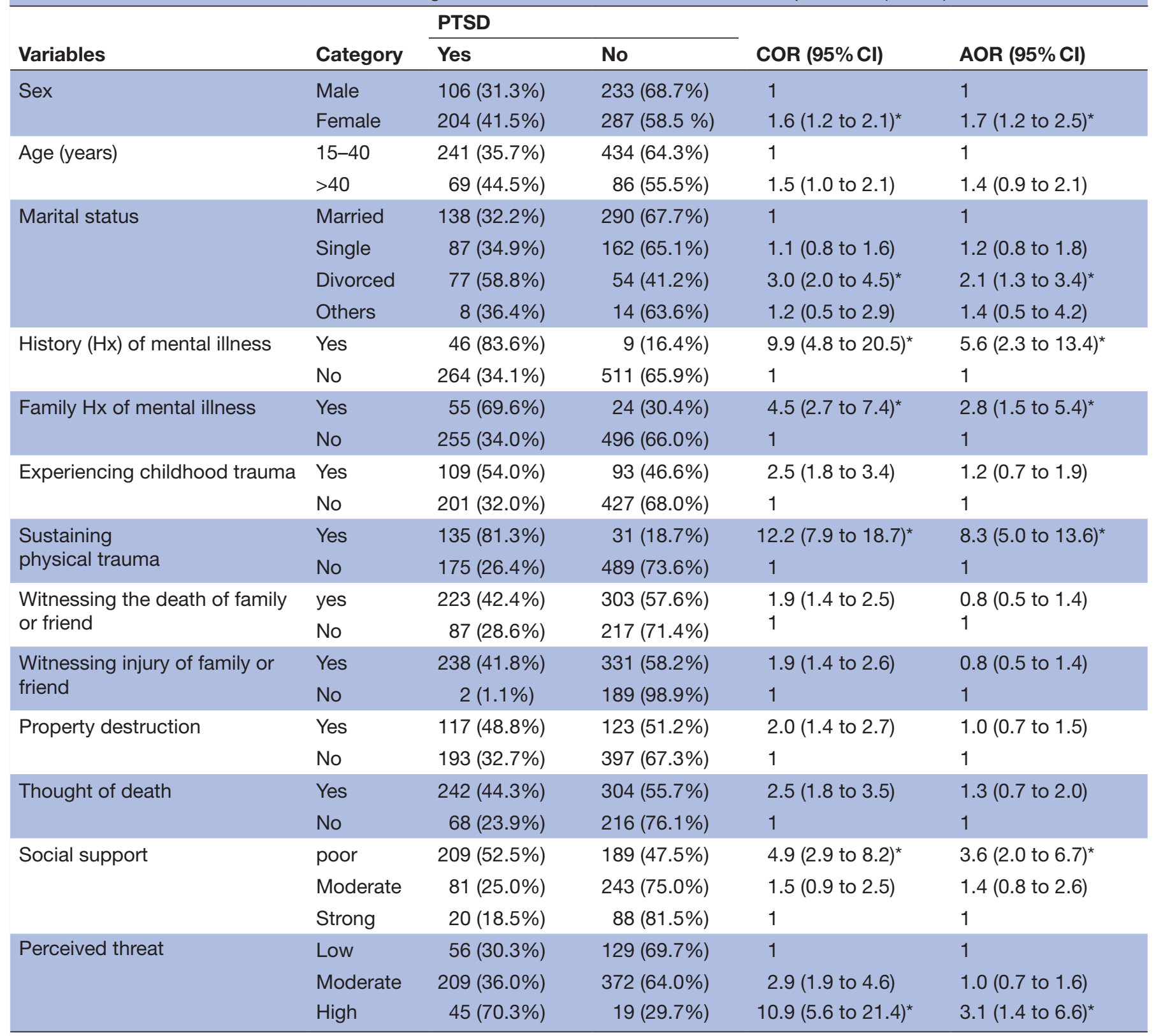

${ }^{*} \mathrm{P}<0.05$, modelfitness $=0.114$ (Hosmer and Lemshow), 0.000 (Omnibus test), no multicolinearity (tolerance $>0.1$ and variance inflation factor $(\mathrm{VIF})<2)$.

COR, crude odd ratio; PTSD, post-traumatic stress disorder.

had low perceived stress. The result is similar with findings from Southern Israel and South Korea. ${ }^{43} 48$ Negative beliefs about the consequence of the ongoing threat as damaging implications will precipitate the onset and persistence of PTSD. ${ }^{49}$

\section{Limitation of the study}

The cross-sectional design of the study prevented us from concluding the casual relationships of the associations we found.

In addition, participants might not tell whether or not they had other PTSD symptoms before the onset of the landslide. The presence of earlier catastrophic experience might have influenced the disorder due to the landslide.

Furthermore, social desirability and recall bias might also be the other limitations. Since the data collection method was a face-to-face interview which might led individuals to respond in socially acceptable ways during the process, especially in cases of substance-related questions.

Individuals without PTSD symptoms may have less motivation to recall earlier exposure than individuals with the symptoms.

In addition, we did not consider other mental health problems that can confound outcomes. For instance, the 
presence and effects of anxiety and depression symptoms, which are commonly associated with PTSD symptoms and the severity of PTSD, duration of mental illness or exposure to other diseases were not covered.

The strength of the study was it used a relatively large sample and sampling methods.

Since we have employed face-to-face interviews, we addressed individuals who had PTSD symptoms for further investigation and intervention.

\section{CONCLUSION}

The prevalence of PTSD was found to be high. This study confirmed that the garbage landslide had a negative impact on the mental health of affected individuals. Female sex, divorce, history of mental illness, family history of mental illness, sustained physical injury, poor social support and high perceived life threat were significantly associated with PTSD. Therefore, we recommend a PTSD-focused early regular screening by trained health professionals and linkage with mental health service providers. It is necessary to give emphasis to individuals with family history of mental illness, women and history of mental illness of those who experienced physical trauma during the disaster.

Acknowledgements The authors acknowledge the University of Gondar and Amanuel Mental Specialized Hospital for funding the study. We extend our gratitude to data collectors, supervisors and study participants for their time and effort. We also thank Mr. Demeke Dessu for his great contribution in language editing of the manuscript.

Contributors SA developed the proposal, supervised the data collection, analyzed the data and wrote the draft manuscript. WG, GL, KH revised the proposal, checked the data analysis. SS, revised the proposal, check data analysis, revised and approved the manuscript.

Funding The authors research have no a specific grant from any funding agency in the public, commercial or not-for-profit sectors.

Competing interests None declared.

Patient consent for publication Not required.

Ethics approval Ethical approval was obtained from Ethical Review Board of the University of Gondar. Ethical clearance was obtained from joint ethical review committees of the University of Gondar and Amanuel mental specialized hospital. A formal letter of permission obtained and submitted to the respective town administration.

Provenance and peer review Not commissioned; externally peer reviewed.

Data sharing statement № additional data is available for this study; all the data are included in the manuscript.

Open access This is an open access article distributed in accordance with the Creative Commons Attribution Non Commercial (CC BY-NC 4.0) license, which permits others to distribute, remix, adapt, build upon this work non-commercially, and license their derivative works on different terms, provided the original work is properly cited, appropriate credit is given, any changes made indicated, and the use is non-commercial. See: http://creativecommons.org/licenses/by-nc/4.0/.

\section{REFERENCES}

1. Heinrichs M, Wagner D, Schoch W, et al. Predicting posttraumatic stress symptoms from pretraumatic risk factors: a 2-year prospective follow-up study in firefighters. Am J Psychiatry 2005;162:2276-86.

2. Association AP. Diagnostic and statistical manual of mental disorders (DSM-5尺): American Psychiatric Pub. 2013.
3. Norris FH, Friedman MJ, Watson PJ, et al. 60,000 Disaster victims speak: part I. An Empirical Review of the Empirical Literature, 1981-2001. Psychiatry 2002;65:207-39.

4. Burkle FM. Acute-phase mental health consequences of disasters: implications for triage and emergency medical services. Ann Emerg Med 1996;28:119-28.

5. Gates MA, Holowka DW, Vasterling JJ, et al. Posttraumatic stress disorder in veterans and military personnel: epidemiology, screening, and case recognition. Psychol Serv 2012;9:361-82.

6. Galea S, Nandi A, Vlahov D. The epidemiology of post-traumatic stress disorder after disasters. Epidemiol Rev 2005;27:78-91.

7. Hg L, Heather Graham L. How Common is PTSD? National Center for PTSD. 2015.:1. National Center for PTSD. 2015:1.

8. Kazour F, Zahreddine NR, Maragel MG, et al. Post-traumatic stress disorder in a sample of Syrian refugees in Lebanon. Compr Psychiatry 2017;72:41-7.

9. Prince M, Patel V, Saxena S, et al. No health without mental health The Lancet 2007;370:859-77.

10. Ayuso-Mateos JL. Global Burden of post-traumatic stress disorder in the year 2000: version 1 estimates. World Health Organ 2002.

11. Kaplan BJ. Kaplan and Sadock's Synopsis of Psychiatry. Behavioral Sciences/Clinical Psychiatry. Tijdschrift voor Psychiatrie 2016;58:78-9.

12. Bleich A, Gelkopf M, Solomon Z. Exposure to terrorism, stressrelated mental health symptoms, and coping behaviors among a nationally representative sample in Israel. JAMA 2003;290:612-20.

13. Kalia M. Assessing the economic impact of stress--the modern day hidden epidemic. Metabolism 2002;51:49-53.

14. Norris FH, Murphy AD, Baker CK, et al. Epidemiology of trauma and posttraumatic stress disorder in Mexico. J Abnorm Psychol 2003;112:646-56.

15. Atwoli L, Stein DJ, Koenen KC, et al. Epidemiology of posttraumatic stress disorder: prevalence, correlates and consequences. Curr Opin Psychiatry 2015;28:307.

16. Ozer EJ, Best SR, Lipsey TL, et al. Predictors of posttraumatic stress disorder and symptoms in adults: a meta-analysis. Psychol Bull 2003;129:52-73.

17. Akinyemi OO, Owoaje $\mathrm{ET}$, Ige OK, et al. Comparative study of mental health and quality of life in long-term refugees and host populations in Oru-ljebu, Southwest Nigeria. BMC Res Notes 2012;5:394.

18. Priebe S, Matanov A, Janković Gavrilović J, et al. Consequences of untreated posttraumatic stress disorder following war in former Yugoslavia: morbidity, subjective quality of life, and care costs. Croat Med J 2009;50:465-75.

19. Keane TM, Marshall AD, Taft CT. Posttraumatic stress disorder: etiology, epidemiology, and treatment outcome. Annu Rev Clin Psychol 2006;2:161-97.

20. Raviteja K, MunwarBasha B. Probabilistic back analysis of Koshe landfill slope failure. Indian geotechnical conference. 2017.

21. Organization WH. Weekly Update on Outbreaks and other Emergencies: Week 11: 11-17 March 2017. Weekly Update on Outbreaks and other Emergencies. 2017.

22. Catapano F, Malafronte R, Lepre F, et al. Psychological consequences of the 1998 landslide in Sarno, Italy: a community study. Acta Psychiatr Scand 2001;104:438-42.

23. Karunakara UK, Neuner F, Schauer M, et al. Traumatic events and symptoms of post-traumatic stress disorder amongst Sudanese nationals, refugees and Ugandans in the West Nile. Afr Health Sci 2004;4:83-93.

24. Ruggiero KJ, Del Ben K, Scotti JR, et al. Psychometric properties of the PTSD Checklist-Civilian Version. J Trauma Stress 2003;16:495-502.

25. Jaranson JM, Butcher J, Halcon L, et al. Somali and Oromo refugees: correlates of torture and trauma history. Am J Public Health 2004;94:591-8.

26. Dalgard OS. The Oslo 3-items social support scale. 20002.

27. COHEN. Perceived Stress Scale. 1983:7-8.

28. Humeniuk R, Ali R, Babor TF, et al. Validation of the alcohol, smoking and substance involvement screening test (ASSIST). Addiction 2008;103:1039-47.

29. Parvaresh N, Bahramnezhad A. Post-traumatic stress disorder in bam-survived students who immigrated to Kerman. four months after the earthquake 2009

30. Ataman M. Prevalence of PTSD and related factors in communities living in conflictual area: Diyarbakir case.. 2008.

31. North CS, Nixon SJ, Shariat S, et al. Psychiatric disorders among survivors of the Oklahoma City bombing. JAMA 1999;282:755-62.

32. Fitch T, Villanueva G, Quadir M, et al. Prevalence and risk factors for PTSD in injured workers in Bangladesh: a study of surviving workers from the Rana Plaza building collapse. Lancet Glob Health 2015;3:S33. 
33. Alghamdi M, Hunt N, Thomas S. Prevalence rate of PTSD, depression and anxiety symptoms among Saudi firefighters. Journal of Traumatic Stress Disorders and Treatment 2016;6:1-6.

34. Tsujiuchi T, Yamaguchi M, Masuda K, et al. High prevalence of posttraumatic stress symptoms in relation to social factors in affected population one year after the Fukushima nuclear disaster. PLoS One 2016;11:e0151807.

35. Mugisha J, Muyinda $\mathrm{H}$, Wandiembe $\mathrm{P}$, et al. Prevalence and factors associated with Posttraumatic Stress Disorder seven years after the conflict in three districts in northern Uganda (The Wayo-Nero Study). BMC Psychiatry 2015;15:170.

36. Lecic-Tosevski D, Pejuskovic B, Miladinovic T, et al. Posttraumatic stress disorder in a Serbian community: seven years after trauma exposure. J Nerv Ment Dis 2013;201:1040-4.

37. Farhood L, Dimassi H, Lehtinen T. Exposure to war-related traumatic events, prevalence of PTSD, and general psychiatric morbidity in a civilian population from Southern Lebanon. J Transcult Nurs 2006;17:333-40.

38. Brunnet AE, Bolaséll LT, Weber J, et al. Prevalence and factors associated with PTSD, anxiety and depression symptoms in Haitian migrants in southern Brazil. Int J Soc Psychiatry 2018;64:17-25.

39. Jenkins R, Othieno $\mathrm{C}$, Omollo $\mathrm{R}$, et al. Probable post traumatic stress disorder in kenya and its associated risk factors: a crosssectional household survey. Int J Environ Res Public Health 2015;12:13494-509.

40. Arnberg FK, Bergh Johannesson K, Michel PO. Prevalence and duration of PTSD in survivors 6 years after a natural disaster. $J$ Anxiety Disord 2013;27:347-52.
41. Zhou X, Kang L, Sun X, et al. Prevalence and risk factors of posttraumatic stress disorder among adult survivors six months after the Wenchuan earthquake. Compr Psychiatry 2013;54:493-9.

42. Heim C, Newport DJ, Heit S, et al. Pituitary-adrenal and autonomic responses to stress in women after sexual and physical abuse in childhood. JAMA 2000;284:592-7.

43. Song JY, Jeong KS, Choi KS, et al. Psychological risk factors for posttraumatic stress disorder in workers after toxic chemical spill in Gumi, South Korea. Workplace Health Saf 2018;66:393-402.

44. Brewin CR, Andrews B, Valentine JD. Meta-analysis of risk factors for posttraumatic stress disorder in trauma-exposed adults. J Consult Clin Psychol 2000;68:748-66.

45. Keane T, Fisher L, Krinsley K, et al. Handbook of prescriptive treatments for adults: Springer, 1994.

46. Kaniasty K, Norris FH. Longitudinal linkages between perceived social support and posttraumatic stress symptoms: sequential roles of social causation and social selection. J Trauma Stress 2008;21:274-81.

47. Guay S, Billette V, Marchand A. Exploring the links between posttraumatic stress disorder and social support: processes and potential research avenues. J Trauma Stress 2006;19:327-38.

48. Besser A, Neria Y, Haynes M. Adult attachment, perceived stress, and PTSD among civilians exposed to ongoing terrorist attacks in Southern Israel. Pers Individ Dif 2009;47:851-7.

49. Taylor S. Clinician's guide to PTSD: A cognitive-behavioral approach: Guilford Publications, 2017. 